\title{
Hypoxia enhances CXCR4 expression by activating HIF-1 in oral squamous cell carcinoma
}

\author{
TOHRU ISHIKAWA ${ }^{1 *}$, KOH-ICHI NAKASHIRO ${ }^{1 *}$, SEBASTIAN K. KLOSEK $^{1 *}$, \\ HIROYUKI GODA ${ }^{1}$, SHINGO HARA ${ }^{1}$ DAISUKE UCHIDA $^{2}$ and HIROYUKI HAMAKAWA ${ }^{1}$ \\ ${ }^{1}$ Department of Oral and Maxillofacial Surgery, Ehime University Graduate School of Medicine, \\ 454 Shitsukawa, Toon, Ehime 791-0295; ${ }^{2}$ Second Department of Oral and Maxillofacial Surgery, \\ Tokushima University School of Dentistry, 3-18-15 Kuramoto, Tokushima, Tokushima 770-8504, Japan
}

Received September 25, 2008; Accepted November 24, 2008

DOI: 10.3892/or_00000275

\begin{abstract}
Hypoxia promotes the invasive and metastatic potential of tumour cells. A recent study has shown that the activation of the chemokine receptor CXCR4 by lack of oxygen in breast cancer is HIF-1-dependent. We have previously demonstrated that CXCR4 signalling is involved in the establishment of lymph node metastasis in oral squamous cell carcinoma (OSCC). In this study, we investigated a correlation between CXCR4 and HIF- $1 \alpha$ expression in OSCC. Immunohistochemistry showed that CXCR4 was expressed in 20 of 85 OSCC tissues, while HIF-1 $\alpha$ was expressed in 51 of 85 samples. There was a significant correlation between the expression of CXCR4 and HIF-1 $\alpha$. In human OSCC cells, hypoxia markedly enhanced the expression of both HIF-1 $\alpha$ and CXCR4. Furthermore, synthetic small interfering RNA specific for HIF-1 $\alpha$ significantly suppressed the expression of this protein, and also attenuated the induction of CXCR4 expression under hypoxic conditions. These results indicated that HIF-1 $\alpha$ regulated hypoxia-induced CXCR4 expression in OSCC.
\end{abstract}

\section{Introduction}

The process of tumour expansion is characterized by rapid growth. Accompanying this rapid growth, there are alterations in the microenvironment of the tumour cells, typically caused by an inability of the local vasculature to supply them with sufficient nutrients and oxygen (1). Human solid tumours

Correspondence to: Dr Koh-ichi Nakashiro, Department of Oral and Maxillofacial Surgery, Ehime University Graduate School of Medicine, 454 Shitsukawa, Toon, Ehime 791-0295, Japan

E-mail: nakako@m.ehime-u.ac.jp

${ }^{*}$ Contributed equally

Key words: CXCR4, HIF-1, hypoxia, oral squamous cell carcinoma contain regions that are significantly hypoxic compared to normal tissue (2). Hypoxia may also be associated with malignant progression and resistance to radiotherapy (3) and chemotherapy (4). Previous studies have shown that in patients suffering from squamous tumours of the head and neck, cervical or breast cancers, hypoxia in the tumours is associated with increased metastasis $(2,5,6)$. Hypoxia induces the expression of hypoxia-inducible factor-1 (HIF-1), which regulates a large number of genes adaptive for hypoxic survival by binding to hypoxia response elements (HRE) within the promoters of genes $(7,8)$, including erythropoietin, glucose transporters, glycolytic pathway enzymes, vascular endothelial growth factor (VEGF), hemeoxygenase and inducible nitric oxide synthase (9). HIF-1 is a heterodimeric basic helix-loop-helix Per-ARNT-Sim (PAS) domain protein that consists of $\alpha$ and $\beta$ subunits (10). Although HIF- $1 \alpha$ is constitutively expressed, HIF- $1 \alpha$ is strictly regulated by cellular oxygen levels (6). HIF- $1 \alpha$ mRNA levels are equivalent in normoxia and hypoxia (11), but the oxygendependent regulation of HIF-1 $\alpha$ occurs at the level of protein degradation (12): under hypoxic conditions, HIF-1 $\alpha$ is stabilized whereas it is degraded by the von Hippel-Lindau (VHL)-E3 ubiquitin ligase complex under normoxic conditions (13). It has been demonstrated that the VHL protein negatively regulates chemokine receptor CXCR4 expression as a result of targeting HIF- $1 \alpha$ for degradation under normoxic conditions (14).

Chemokines are a superfamily of small cytokine-like proteins, identified as chemoattractants controlling the migration of leucocytes, especially during immune and inflammatory reactions $(15,16)$. Chemokines are classified into $C$, $\mathrm{CC}, \mathrm{CXC}$ and $\mathrm{CX} 3 \mathrm{C}$ chemokines, based on the presence and spacing of four conserved cysteine residues (17-19). Chemokines are also important in dendritic cell maturation, B and $\mathrm{T}$ cell development, Th1 and Th2 responses, infections, angiogenesis and tumour growth (15). The specific effects of chemokines on their target cells are mediated by seven transmembrane spanning, $\mathrm{G}$ protein coupled receptors. The chemokine receptor CXCR4 is a member of the CXCR subfamily $(15,16)$ and is highly expressed by breast cancer cells; these cells preferentially metastasize to sites that produce large amounts of the CXCR4-specific ligand, stromal 
cell-derived factor-1 (SDF-1) (20). Recently, we have also demonstrated that SDF-1/CXCR4 signalling plays a critical role in the establishment of lymph node metastases in oral squamous cell carcinoma OSCC (21).

In this study, we evaluated the correlation between CXCR4 and HIF-1 $\alpha$ expression in OSCC tissues and the regulation of CXCR4 expression by HIF-1 $\alpha$ under hypoxic conditions using cultured OSCC cells.

\section{Materials and methods}

Patients and tissues. OSCC tissues were obtained from 85 patients undergoing primary cancer resection at the Department of Oral and Maxillofacial Surgery, Ehime University Hospital from 1991 to 2001. The clinical stage was defined according to the TNM classification of malignant tumours (International Union Against Cancer), and tumour differentiation was graded by the criteria proposed by the World Health Organization (22). Histological malignancy (i.e. mode and stage of invasion) was determined on the basis of Anneroth's classification (23).

Immunohistochemistry. Tissue samples were fixed in $10 \%$ buffered formalin and embedded in paraffin. Tissue sections were cut $(4 \mu \mathrm{m})$, deparaffinized with xylene, and rehydrated through graduated ethanol solutions. The slides were treated with target retrieval solution (Dako, Carpenteria, CA) at $97^{\circ} \mathrm{C}$ for $45 \mathrm{~min}$. Further, the sections were treated with $3 \%$ hydrogen peroxide in methanol for $30 \mathrm{~min}$ to quench endogenous peroxidase activity. Non-specific reactions were then blocked with $5 \%$ dried milk in phosphate-buffered saline (PBS) for $1 \mathrm{~h}$ at room temperature and the sections incubated overnight at $4{ }^{\circ} \mathrm{C}$ with rabbit anti-human HIF-1 $\alpha$ monoclonal antibody (1:50; Millipore, Bedford, MA) or rabbit anti-CXCR4 polyclonal antibody (1:100; ProSci, Poway, CA). Multi-use secondary antibody (EnVision System; Dako) was applied to the tissues for $1 \mathrm{~h}$ at room temperature. Peroxidase activity was visualized with a 3,3'-diaminobenzidine tetrahydrochloride solution containing $0.05 \%$ hydrogen peroxidase (DAB Liquid System; Dako) and the sections were counterstained with haematoxylin for $3 \mathrm{~min}$, dehydrated through graduated ethanol solutions, cleared with xylene, and mounted. Staining intensity was evaluated by systematically screening all slices and evaluating them according to an established 0-3 scale. The immunohistochemical results for HIF- $1 \alpha$ protein were classified as follows: 0 , no staining; 1 , nuclear staining in $<1 \%$ of cells; 2 , nuclear staining in $1-10 \%$ of cells and/or weak cytoplasmic staining; 3 , nuclear staining in $>10 \%$ of cells and/or distinct or strong cytoplasmic staining. For CXCR4 protein, the membrane staining and/or cytoplasmic staining were evaluated. Samples graded as 0 and 1 were considered negative, 2 and 3 as positive.

Statistical analysis. All calculations were performed using the Statview 5.1 computer program (Avacus, NC). Spearman's rank correlation was used to determine whether a correlation between CXCR4 and HIF-1 $\alpha$ expression was positive or negative. The expression of these proteins and clinicopathological parameters were evaluated using Fisher's exact test. All P-values $<0.05$ were considered statistically significant.
Table I. Correlation between the expression of CXCR4 and HIF-1 $\alpha$ in OSCC.

\begin{tabular}{lccc}
\hline & \multicolumn{2}{c}{ HIF-1 $\alpha$} & \\
\cline { 2 - 3 } CXCR4 & Negative & Positive & Total \\
\hline Negative & $32(38 \%)$ & $33(39 \%)$ & $65(77 \%)$ \\
Positive & $2(2 \%)$ & $18(21 \%)$ & $20(23 \%)$ \\
Total & $34(40 \%)$ & $51(60 \%)$ & $85(100 \%)$ \\
\hline
\end{tabular}

Spearman's rank correlation, $\mathrm{P}=0.002$.

Cells and cell culture. HSC-2, HSC-3, SCC25, and KB cells (Japanese Collection of Research Bioresources, Tokyo, Japan) derived from human OSCC tumours were used. Cells were maintained in DMEM/F-12 medium (Sigma-Aldrich, St. Louis, MO) supplemented with $10 \%$ heat-inactivated foetal bovine serum (FBS; Biosource International, Camarillo, CA), $100 \mathrm{U} /$ $\mathrm{ml}$ penicillin, and $100 \mu \mathrm{g} / \mathrm{ml}$ streptomycin (Invitrogen, Carlsbad, CA), referred to as the complete medium, and incubated in a humidified atmosphere of $95 \%$ air and $5 \% \mathrm{CO}_{2}$ at $37^{\circ} \mathrm{C}$. For hypoxic conditions, cells were cultured at $37^{\circ} \mathrm{C}$ in $94 \% \mathrm{~N}_{2}, 5 \% \mathrm{CO}_{2}$, and $1 \% \mathrm{O}_{2}$.

Western blot analysis. Cells grown in monolayers were harvested when subconfluent and lysed in phosphate-buffered saline (PBS) containing 1\% nonidet P-40, $0.5 \%$ sodium deoxycholate, $0.1 \%$ sodium dodecyl sulphate (SDS), $0.1 \mathrm{M}$ $\mathrm{NaF}, 10 \mathrm{mg} / \mathrm{ml}$ leupeptin, $0.1 \mathrm{mg} / \mathrm{ml}$, aprotinin, and $50 \mathrm{mg} / \mathrm{ml}$ phenylmethylsulphonyl fluoride (PMSF) (all reagents from Sigma-Aldrich). Following sonication and incubation on ice for $30 \mathrm{~min}$, the supernatants of samples were separated by SDS-PAGE (Bio-Rad, Hercules, CA) and transferred to a polyvinylidene difluoride (PVDF) membrane (Millipore). The membranes were blocked with $5 \%$ non-fat dried milk (Wako, Osaka, Japan), in T-TBS (25 mM Tris-HCl, $125 \mathrm{mM}$ $\mathrm{NaCl}, 0.1 \%$ Tween-20; Sigma-Aldrich) overnight at $4^{\circ} \mathrm{C}$, probed with primary antibodies (anti-HIF-1 $\alpha$; Novus Biologicals, Littleton, $\mathrm{CO}$ and anti-CXCR4; ProSci) overnight at $4^{\circ} \mathrm{C}$ and then with horseradish peroxidase-conjugated secondary antibodies against rabbit or mouse IgG (GE Healthcare Bio-Sciences, Piscataway, NJ) for $1 \mathrm{~h}$. The immune complexes were visualized with the enhanced chemiluminescence (ECL) Plus kit (GE Healthcare Bio-Sciences) according to the manufacturer's protocol. As an internal control, the blots were stripped with $62.5 \mathrm{mM}$ Tris- $\mathrm{HCl}$ (pH 6.8) buffer containing $0.7 \%$ 2-mercaptoethanol and 2\% SDS (SigmaAldrich) at $50^{\circ} \mathrm{C}$ for $30 \mathrm{~min}$ and re-probed with mouse anti- $\beta$ tubulin monoclonal antibody (Becton Dickinson Biosciences, San Jose, CA).

$R N A$ isolation and reverse transcription-polymerase chain reaction $(R T-P C R)$. Total RNA was extracted using the RNA isolation solution, Isogen (Nippon Gene, Toyama, Japan), according to the manufacturer's instructions and subjected to cDNA synthesis with the use of QuantiTect Reverse transcription kit (Qiagen, Valencia, CA) according to the 
Table II. Clinicopathological profiles of OSCC patients and CXCR4 and HIF-1 $\alpha$ immunoreactivity

\begin{tabular}{|c|c|c|c|c|c|}
\hline & No. & CXCR4 positive & $\mathrm{P}$ & HIF-1 $\alpha$ positive & $\mathrm{P}$ \\
\hline Age, years & & & NS & & NS \\
\hline$\leq 60$ & 66 & $17(26 \%)$ & & $39(59 \%)$ & \\
\hline$>60$ & 19 & $3(16 \%)$ & & $12(63 \%)$ & \\
\hline $\mathrm{T}$ stage & & & NS & & NS \\
\hline $\mathrm{T} 1$ and $\mathrm{T} 2$ & 61 & $15(25 \%)$ & & $39(64 \%)$ & \\
\hline $\mathrm{T} 3$ and $\mathrm{T} 4$ & 24 & $5(21 \%)$ & & $12(50 \%)$ & \\
\hline Lymph nodes & & & 0.019 & & NS \\
\hline Negative & 50 & $7(14 \%)$ & & $33(66 \%)$ & \\
\hline Positive & 35 & $13(37 \%)$ & & $18(51 \%)$ & \\
\hline Differentiation & & & NS & & NS \\
\hline Well/moderate & 66 & $14(21 \%)$ & & $42(64 \%)$ & \\
\hline Poor & 19 & $6(32 \%)$ & & $9(47 \%)$ & \\
\hline Pattern of invasion & & & NS & & NS \\
\hline Grade 1-2 & 24 & $5(21 \%)$ & & $18(75 \%)$ & \\
\hline Grade 3-4 & 61 & $15(25 \%)$ & & $33(54 \%)$ & \\
\hline
\end{tabular}

NS, not significant.

manufacturer's recommendations. Quantification of mRNA levels was carried out by real-time quantitative PCR, using TaqMan PCR. Specific cDNAs and porphobilinogen deaminase (PBGD) cDNA, as an internal control, were PCRamplified separately using an oligonucleotide probe labelled with a 5'-fluorescent reporter dye and a 3'-quencher dye. Each PCR amplification was performed in a $20 \mu 1$ final reaction mixture consisting of $10 \times$ LightCycler-FastStart DNA Master mix (Roche Diagnostics, Mannheim, Germany), $450 \mathrm{nM}$ forward primer, $450 \mathrm{nM}$ reverse primer, $250 \mathrm{nM}$ TaqMan probe and $2 \mu \mathrm{lcDNA}$. The thermal cycling conditions comprised an initial step at $95^{\circ} \mathrm{C}$ for $10 \mathrm{~min}$, followed by 45 cycles at $95^{\circ} \mathrm{C}$ for $10 \mathrm{sec}, 60^{\circ} \mathrm{C}$ for $10 \mathrm{sec}$, and $72^{\circ} \mathrm{C}$ for 5 sec. Primers and TaqMan probes for the CXCR4 gene were purchased from TaqMan gene expression assays (Applied Biosystems). The 5'-fluorescent reporter dye was cleaved from the cDNA by the 5'-nuclease activity of Taq DNA polymerase and its fluorescence was detected with the LightCycler (Roche Diagnostics). Automated calculations were performed by the second derivative maximum method (LC software, version $3.5)$.

Synthetic small interfering RNAs (siRNAs), plasmids, and transfection. Synthetic siRNA specific for HIF-1 $\alpha$ (siHIF-1 $\alpha)$ or VHL (siVHL) was purchased from Dharmacon (Lafayette, $\mathrm{CO}$ ) or B-Bridge (Mountain View, CA), respectively. The RNA duplexes were resuspended in RNase-free annealing buffer (20 mM KCl, 6 mM HEPES-KOH (pH 7.5), $0.2 \mathrm{mM}$ $\mathrm{MgCl}_{2}$ ) to a final concentration of $20 \mu \mathrm{M}$. Synthetic siRNA specific for green fluorescent protein (GFP) (siGFP; Dharmacon) was used as a negative control. Luciferase reporter plasmid constructs carrying the CXCR4 wild and mutated promoter were a generous gift from Dr W. Krek (14). Cells were seeded at a density of $8 \times 10^{5}$ per well in $60-\mathrm{mm}$ culture dishes in complete medium. Transfection was performed $24 \mathrm{~h}$ later with Lipofectamine 2000 reagent (Invitrogen) mixed with $10 \mathrm{nM}$ of siRNA. The luciferase activity was measured with the use of dual-luciferase reporter assay system (Promega, Madison, WI) and a luminometer (Gene Light 55; Nition, Funabashi, Japan).

\section{Results}

Immunohistochemical expression of HIF-1 $\alpha$ and CXCR4 in OSCC tissues. Paraffin-embedded tissue samples from 85 tumour patients were labelled for HIF-1 $\alpha$ and CXCR4 immunohistochemically. Of the 85 OSCC tissues, 51 (60\%) showed mainly nuclear, but also cytoplasmic HIF-1 $\alpha$ staining in the perinecrotic region of the tumour. We detected CXCR4 in 20/85 (23\%) OSCC tissues, on the cell membrane and in the cytoplasm; the labelling was frequently especially strong at the infiltrating tumour front, suggesting CXCR4 expression may be up-regulated in these areas. Of the positive CXCR4 samples, 90\% (18/20) proved to be positive for HIF-1 $\alpha$ (Table I), and this association was highly significant ( $\mathrm{P}=0.002$, Spearman's rank correlation).

We also analyzed the association between CXCR4 or HIF- $1 \alpha$ immunostaining and various clinicopathological parameters of the OSCCs. Increased levels of CXCR4 expression were correlated with lymph node grade $(\mathrm{P}=0.019)$, but not with age, tumour stage, differentiation, or mode of invasion (Table II). Increased levels of HIF-1 $\alpha$ expression did not correlate with any of the above clinicopathological factors (Table II). 


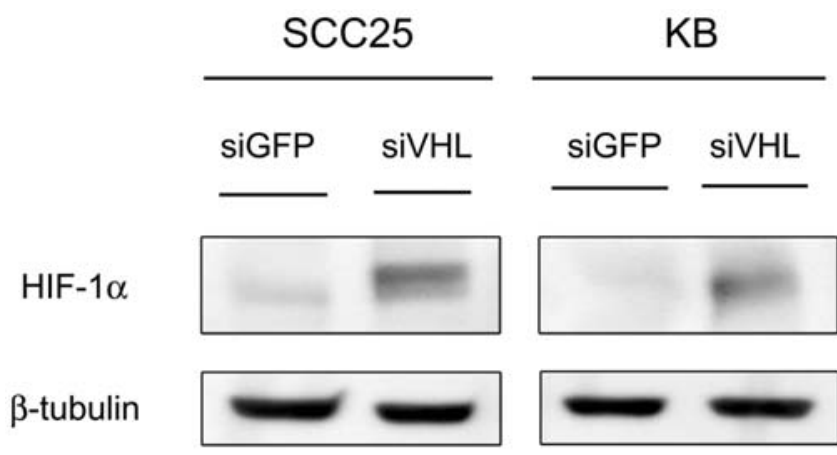

Figure 1. Levels of HIF-1 $\alpha$ protein in normoxic conditions in VHL-suppressed cells by Western blotting. siVHL-transfected SCC 25 and KB cells showed HIF-1 $\alpha$ accumulation in normoxia. siGFP-transfected cells were used as controls.

Stabilization of HIF-la under normoxic conditions by knockdown of VHL expression in human OSCC cell. The product of the VHL tumour suppressor gene is the recognition component of the E3-ubiquitin ligase complex that targets HIF-1 $\alpha$ for ubiquitination. This ubiquitination occurs only in the presence of oxygen, in normoxic conditions. We examined the effect of VHL suppression on HIF-1 $\alpha$ protein levels under normoxic conditions in SCC25 and KB cells. Stabilization and accumulation of HIF-1 $\alpha$ protein was observed by transfection of siVHL at the concentration of $10 \mathrm{nM}$ (Fig. 1).

Hypoxia-induced expression of CXCR4 and HIF-1a in human OSCC cells. HSC-2, HSC-3, SCC25, and KB cells were cultured under hypoxic conditions for different periods and the expression levels of CXCR4 mRNA were determined by real-time quantitative RT-PCR. After exposure to hypoxia for $24 \mathrm{~h}$, expression of $C X C R 4$ mRNA was markedly enhanced in these cells by $\sim 28-, 4-, 26-$, and 38 -fold, respectively (Fig. 2A). Therefore, the expression of CXCR 4 and HIF- $1 \alpha$ protein was also analysed by Western blotting in these cells after exposure to normoxic or hypoxic conditions for $24 \mathrm{~h}$. Hypoxia induced the expression of both CXCR 4 and HIF-1 $\alpha$ protein in all cell lines (Fig. 2B). Furthermore, hypoxiainduced CXCR4 expression in human OSCC cells was examined using a luciferase reporter plasmid containing CXCR4 promoter fragment with HIF1- $\alpha$ response elements. Hypoxia enhanced the luciferase activity in $\mathrm{SCC} 25$ and $\mathrm{KB}$ cells $\sim 4.8-$ and 5.12-fold, respectively. Luciferase reporter activation was normalized by reporter activity of plasmid carrying mutant CXCR4 promoter (Fig. 2C).

Regulation of CXCR4 expression by HIF-1a in hypoxia. We used RNA interference (RNAi) methods to test whether HIF- $1 \alpha$ regulates hypoxia-induced CXCR 4 expression. Synthetic siHIF- $1 \alpha$ was transfected into HSC-2, HSC-3, SCC25, and KB cells. After $24 \mathrm{~h}$ in hypoxic conditions, transfection of siHIF-1 $\alpha$ markedly reduced the expression of HIF-1 $\alpha$ protein compared to control siGFP (Fig. 3A), and suppressed CXCR4 mRNA expression by $92,76,80$, and $90 \%$ in HSC2, HSC-3, SCC25 and KB cells, respectively (Fig. 3B). Furthermore, siHIF- $1 \alpha$ also inhibited the expression of CXCR 4 protein in hypoxic conditions (Fig. 3A). Co-transfection of
A

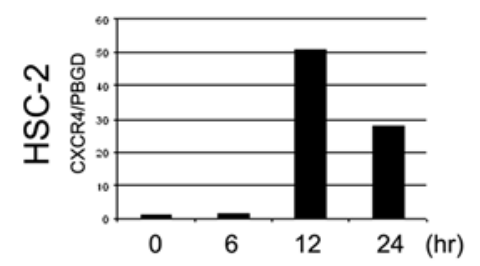

B
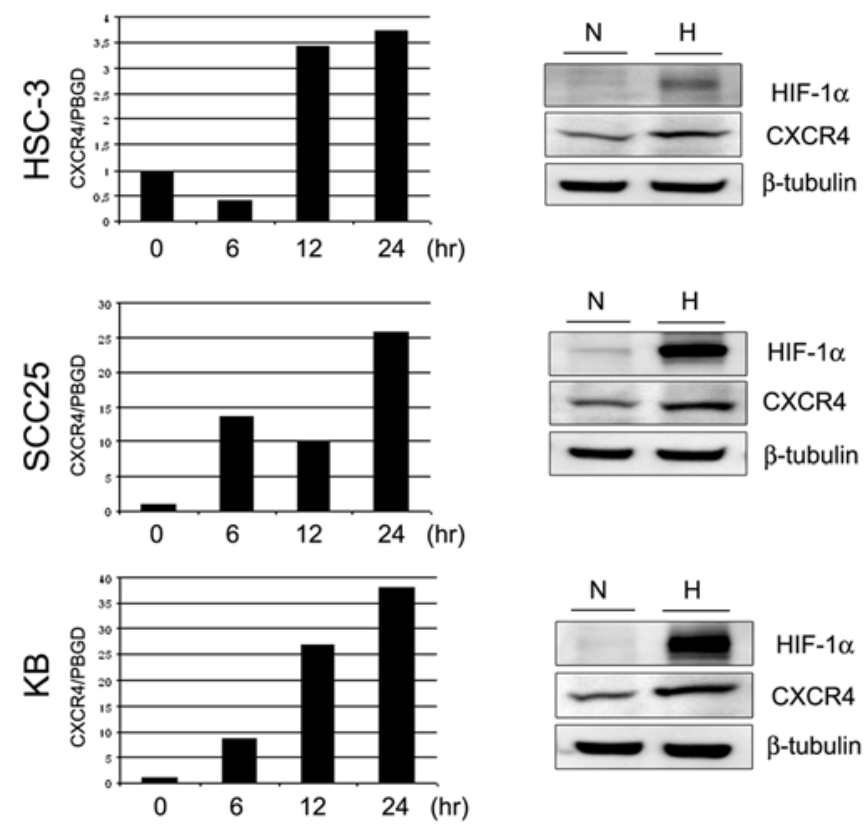

C
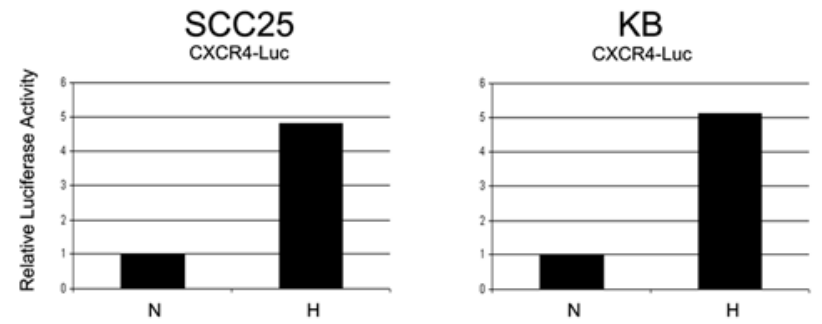

Figure 2. Effect of hypoxia on CXCR4 expression in OSCC cell lines. Cells were cultured for indicated time under hypoxic conditions. Total RNA was analyzed by real-time quantitative RT-PCR for CXCR4 expression (A). Cells were cultured for $24 \mathrm{~h}$ under normoxic or hypoxic conditions. Cell lysates were analyzed by Western blotting for CXCR 4 and HIF-1 $\alpha$ expression (B). Luciferase activity increased under hypoxic conditions in cells transfected with plasmid carrying wild-type CXCR4 promoter. Normalization by luciferase activity derived from mutant type CXCR4 promoter transfectants (C).

SCC25 and KB cells with a luciferase reporter plasmid containing CXCR4 promoter and siHIF-1 $\alpha$ reduced the luciferase activity (Fig. 3C). These results indicated that hypoxia-induced CXCR4 expression was regulated by HIF- $1 \alpha$ in human OSCC cells.

\section{Discussion}

In contrast to the situation in normal organs, tissue oxygenation in human primary tumours is not well regulated, and the $\mathrm{pO}_{2}$ of the tissues is often markedly low $(2,6)$. Low oxygen tensions increase the levels of HIF-1 in cancer cells and this 
A
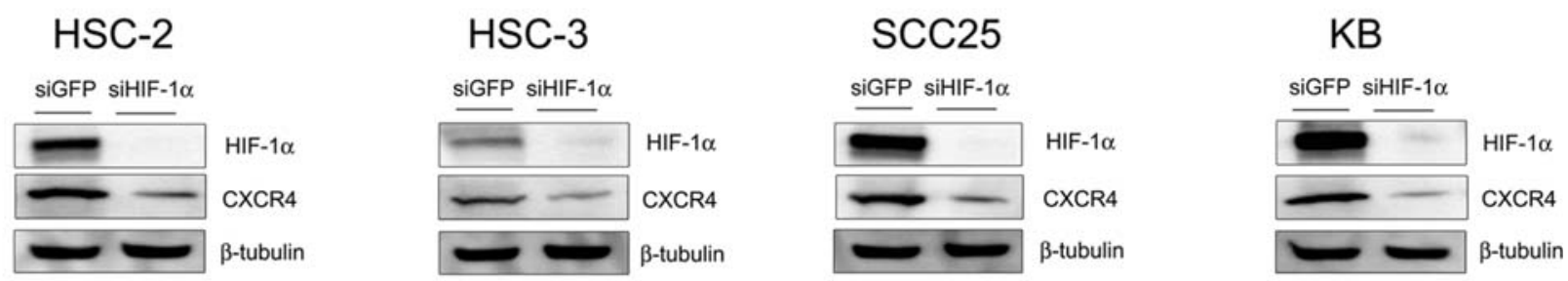

B
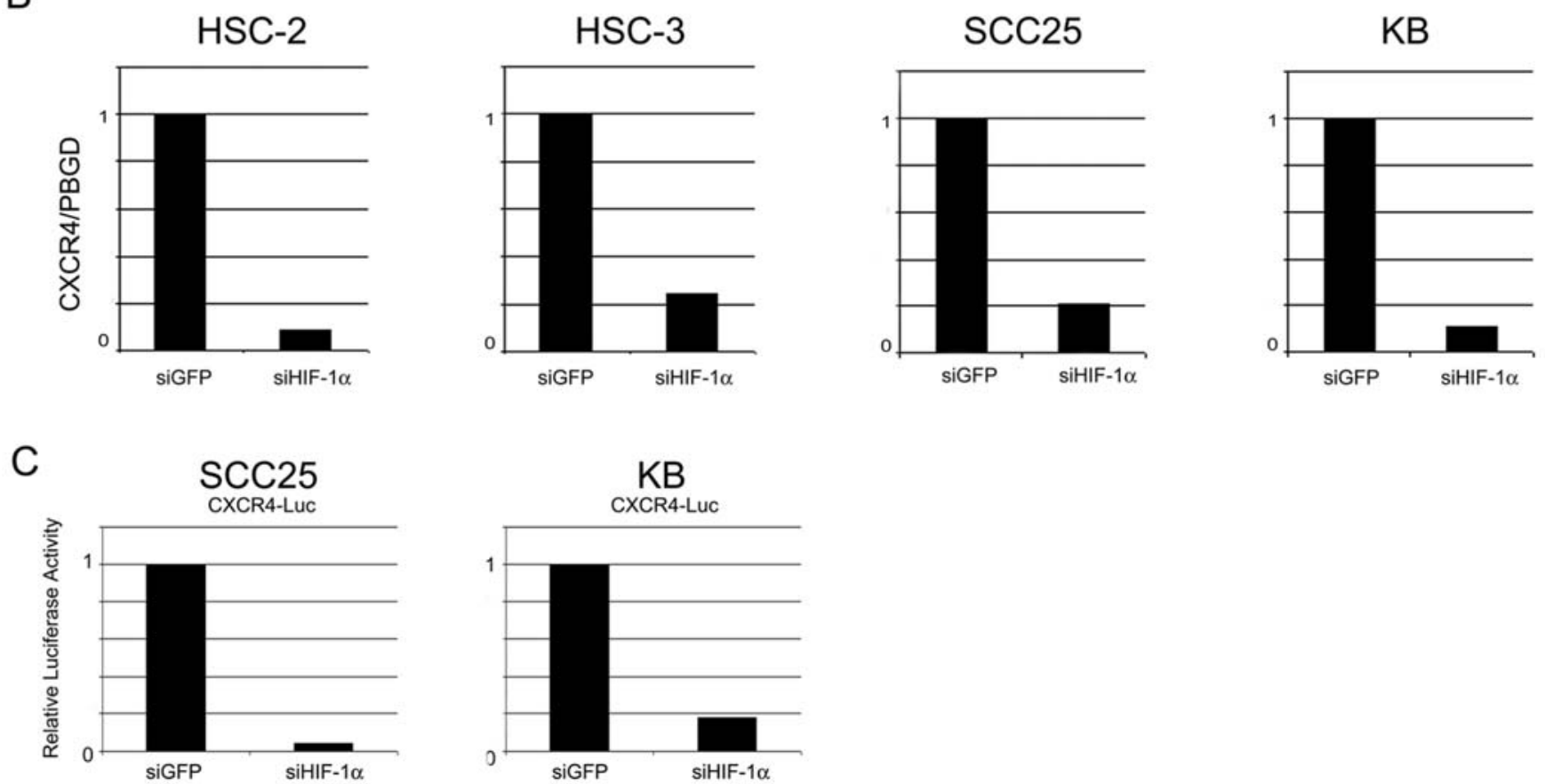

Figure 3. Inhibition of CXCR4 expression by siRNA specific for HIF-1 $\alpha$ under hypoxic conditions in OSCC cell lines. Cells were transfected with siHIF-1 $\alpha$ and then incubated in hypoxic conditions for $24 \mathrm{~h}$. Cell lysates were prepared and analyzed by Western blotting for CXCR 4 and HIF- $1 \alpha$ expression. siHIF-1 $\alpha$ significantly reduced the expression of CXCR4 and HIF-1 $\alpha$ under hypoxic conditions (A). Total RNA was prepared and analyzed by real-time quantitative RT-PCR for CXCR4 mRNA expression (B). siHIF-1 $\alpha$ inhibited the increase of reporter activity under hypoxic conditions in cells carrying CXCR promoterluciferase. Control cells were transfected with siGFP. Normalization by luciferase activity derived from mutant type CXCR4 promoter transfectants (C).

transcriptional factor is one of the major regulators of the cellular response to hypoxia $(7,8)$. The HIF-1 $\alpha$ subunit is detectable in the nucleus of normoxic cells whereas the HIF-1 $\alpha$ subunit is undetectable in most cell types due to its rapid degradation by the ubiquitin-proteasome system (12). The product of the $V H L$ gene is thought to mediate the recognition of HIF- $1 \alpha$ under normoxic conditions, form a complex with it and target it for degradation (13). We demonstrated that VHL protein can function in human OSCC cells, using RNAi method. In hypoxic conditions, HIF- $1 \alpha$ protein accumulated in OSCC cells, which is likely to result from decreased ubiquitination and degradation by VHL. Staller and colleagues demonstrated that HIF-1 activated the transcription of CXCR4 mRNA under hypoxic conditions in human renal carcinoma cell lines (14). Deletion analysis of the CXCR4 promoter using luciferase-reporter constructs implicated HIF- $1 \alpha$ in mediating the induction of CXCR4 expression by hypoxia (14). In our study, when the abovementioned plasmids were used, the reporter activity increased under hypoxic conditions, thereby supporting the previous data. It should be noted that, as well as HIF-1 $\alpha$ levels,
CXCR4 mRNA and protein levels increased in all human OSCC cell lines after $24 \mathrm{~h}$ under hypoxic conditions. To identify whether HIF-1 $\alpha$ was essential for the induction of CXCR4 expression by hypoxia in these cells, we used RNAi methods to inhibit HIF- $1 \alpha$ expression. Depletion of endogenous HIF-1 $\alpha$ by siRNA treatment did indeed inhibit the increase in CXCR4 expression induced by hypoxia in all OSCC cells tested. Our findings suggested an integral role for HIF- $1 \alpha$ in the induction of CXCR4 expression under hypoxic conditions in OSCC cell lines.

CXCR4 is a chemokine receptor initially described as having a role in the homing of lymphocytes to inflammation. It has been suggested that CXCR4 and SDF-1 interactions played a critical role in determining the metastatic destination of breast cancer cells, being associated with actin polymerization and pseudopodia formation, and subsequently inducing motility and invasive responses (20). SDF-1 is maximally expressed in organs to which breast cancer metastases initially spread. Moreover, in in vivo studies, neutralizing the interactions of SDF-1 and CXCR4 significantly impaired metastasis of breast cancer cells to regional lymph nodes 
(20). In this study, we found no correlation between the expression of CXCR4 and HIF-1 $\alpha$ and several clinicopathological parameters, specifically the $\mathrm{T}$ stage classification, tumour differentiation, and mode of invasion. However, CXCR4 expression was significantly correlated with the presence of lymph node metastases. A previous study showed that HIF- $1 \alpha$ expression was highly correlated with $\mathrm{T}$ stage classification and lymph node metastasis in oesophageal squamous cell carcinoma (24). Furthermore, we found a significant correlation between CXCR4 and HIF-1 $\alpha$ expression in OSCC tissues. However, we observed that $39 \%$ of HIF-1 $\alpha$ positive samples were CXCR4-negative. The previous data suggest that overexpression of HIF- $1 \alpha$ may occur very early in carcinogenesis, before histological evidence of angiogenesis or invasion (25). Furthermore, it has been postulated that certain hypoxia-regulated RNA binding factors may interact and stabilize the $C X C R 4 \mathrm{mRNA}$ at the posttranscriptional level (26). Therefore, we consider that the above $39 \%$ of cases might result from the lack of additional mechanisms of control needed for stable CXCR4 presence in cancer tissue.

We have previously demonstrated that CXCR4 signalling is involved in the establishment of lymph node metastasis in OSCC by activating Src family kinases which in turn activate the extracellular signal-regulated kinase (ERK1/2) and Akt/ protein kinase (21). In this study, we showed that hypoxia induced the transcription of the CXCR4 gene, by activating the transcriptional factor HIF- $1 \alpha$, and thus elucidated a mechanism for the establishment of lymph node metastasis in OSCC. Improving the oxygenation of tumour tissues and targeting the HIF-1/CXCR4 signalling pathway appear to be novel approaches to the treatment of OSCC.

\section{Acknowledgements}

This study was supported, in part, by a Grant-in-Aid for Scientific Research from the Ministry of Education, Science, Sports, and Culture of Japan.

\section{References}

1. Vaupel O, Kallinowski F and Okunieff P: Blood flow, oxygen consumption and tissue oxygenation of human tumors. Adv Exp Med Biol 277: 895-905, 1990.

2. Hockel M and Vaupel P: Tumor hypoxia: definitions and current clinical, biologic, and molecular aspects. J Natl Cancer Inst 93 266-276, 2001

3. Gray LH, Conger AD, Ebert M, Hornsey S and Scott OC: Concentration of oxygen dissolved in tissues at the time of irradiation as a factor in radiotherapy. Br J Radiol 26: 638-648, 1953

4. Murphy BJ, Laderoute KR, Chin RJ and Sutherland RM: Metallothionein IIA is up-regulated by hypoxia in human A431 squamous carcinoma cells. Cancer Res 54: 5808-5810, 1994.

5. Hockel M, Schlenger K, Aral B, Mitze M, Schaffer U and Vaupel P: Association between tumor hypoxia and malignant progression in advanced cancer of the uterine cervix. Cancer Res 56: 4509-4515, 1996.

6. Kizaka-Kondoh S, Inoue M, Harada H and Hiraoka M: Tumor hypoxia: A target for selective cancer therapy. Cancer Sci 94 1021-1028, 2003.

7. Semenza GL, Roth PH, Fang HM and Wang GL: Transcriptional regulation of genes encoding glycolytic enzymes by hypoxiainducible factor 1 alpha. J Biol Chem 269: 23757-23763, 1994.
8. Iyer N, Kotch L, Agani F, Leung SW, Laughner E, Wenger RH, Gassmann M, Gearhart JD, Lawler AM, Yu AY and Semenza GL: Cellular and developmental control of $\mathrm{O}_{2}$ homeostasis by hypoxia-inducible factor 1 alpha. Genes Dev 12: 149-162, 1998.

9. Semenza GL: Regulation of mammalian $\mathrm{O}_{2}$ homeostasis by hypoxia-inducible factor 1. Annu Rev Cell Dev Biol 15: 551-578, 1999.

10. Wang GL, Jiang BH, Rue EA and Semenza GL: Hypoxiainducible factor 1 is a basic-helix-loop-helix-PAS heterodimer regulated by cellular $\mathrm{O}_{2}$ tension. Proc Natl Acad Sci USA 92: 5510-5514, 1995.

11. Wenger RH, Kvietikova I, Rolfs A, Gassmann M and Marti HH: Hypoxia-inducible factor- 1 alpha is regulated at post-mRNA level. Kidney Int 51: 560-563, 1997.

12. Huang LE, Gu J, Schau M and Bunn HF: Regulation of hypoxia-inducible factor 1 alpha is mediated by an $\mathrm{O}_{2}$ dependent degradation domain via the ubiquitin-proteasome pathway. Proc Natl Acad Sci USA 95: 7987-7992, 1998.

13. Maxwell PH, Wiesener MS, Chang GW, Clifford SC, Vaux EC, Cockman ME, Wykoff CC, Pugh CW, Maher ER and Ratcliffe PJ: The tumour suppressor protein VHL targets hypoxia-inducible factors for oxygen-dependent proteolysis. Nature 399: 271-275, 1999.

14. Staller P, Sulltkova J, Lisztwan J, Moch H, Oakeley EJ and Krek W: Chemokine receptor CXCR4 downregulated by von Hippel-Lindau tumour suppressor pVHL. Nature 425: 307-311, 2003.

15. Rossi D and Zlotnik A: The biology of chemokines and their receptors. Annu Rev Immunol 18: 217-242, 2000.

16. Zlotnik A and Yoshie O: Chemokines: a new classification system and their role in immunity. Immunity 12: 121-127, 2000.

17. Kelner GS, Kennedy J, Bacon KB, Kleyensteuber S, Largaespada DA, Jenkis NA, Copeland NG, Bazan JF, Moore KW, Schall TJ and Zlotnik A: Lymphotactin: A cytokine that represents a new class of chemokines. Science 266: 1395-1399, 1994

18. Baggiolini M, Dewald B and Moser B: Human chemokines: an update. Annu Rev Immunol 15: 675-705, 1997.

19. Bazan JF, Bacon KB, Hardiman G, Wang W, Soo K, Rossi D, Greaves DR, Zlotnik A and Schall TJ: A new class of membrane-bound chemokine with a $\mathrm{CX}_{3} \mathrm{C}$ motif. Nature 385: 640-644, 1997.

20. Muller A, Homey B, Soto H, Ge N, Catron D, Buchanan ME, McClanahan T, Murphy E, Yuan W, Wagner SN, Barrera JL, Mohar A, Verastegul E and Zlotnik A: Involvement of chemokine receptors in breast cancer metastasis. Nature 410: 50-56, 2001.

21. Uchida D, Begum NM, Almofti A, Nakashiro K, Kawamata H, Tateishi Y, Hamakawa H, Yoshida H and Sato M: Possible role of stromal cell-derived factor-1/CXCR4 signalling on lymph node metastasis of oral squamous cell carcinoma. Exp Cell Res 290: 289-302, 2003.

22. Wasi PN, Cohen B, Luthra UK and Torloni H: Histological typing of oral and oropharyngeal tumors. In: International Histological Classification of Tumor. WHO, Geneva, pp17-18, 1971

23. Anneroth G, Batsakis J and Lunba M: Review of the literature and a recommended system of malignancy grading in oral squamous cell carcinomas. Scand J Dent Res 95: 229-249, 1987.

24. Kurokawa T, Miyamoto M, Kato K, Cho Y, Kawarada Y, Hida Y, Shinohara T, Itoh T, Okushiba S, Kondo $S$ and Katoh $H$ : Overexpression of hypoxia-inducible-factor 1 alpha (HIF-1 alpha) in oesophageal squamous cell carcinoma correlates with lymph node metastasis and pathologic stage. Br J Cancer 89: 1042-1047, 2003

25. Zhong H, De Marzo AM, Laughner E, Lim M, Hilton DA, Zagzag D, Buechler P, Isaacs WB, Semenza GL and Simons JW: Overexpression of hypoxia-inducible factor 1alpha in common human cancers and their metastases. Cancer Res 59: 5830-5835, 1999.

26. Schioppa T, Uranchimeg B, Saccani A, Biswas SK, Doni A, Rapisarda A, Bernasconi S, Saccani S, Nebuloni M, Vago L, Mantovani A, Melillo G and Sica A: Regulation of the chemokine receptor CXCR4 by hypoxia. J Exp Med 198: 1391-1402, 2003. 